\title{
Temperamental Dimension and Anxiety Problems in a Clinical Sample of Three- to Six-year old Children: A Study of Variables
}

\author{
Andrés Laredo ${ }^{1}$, María Claustre Jané ${ }^{1}$, Ferran Viñas ${ }^{2}$, Mercé Mitjavila ${ }^{1}$, \\ Ester $\mathrm{Pla}^{3}$, Maite $\mathrm{Pi}^{4}$, Gloria Ruiz ${ }^{5}$, and Edelmira Domènech ${ }^{1}$ \\ ${ }^{1}$ Universitat Autònoma de Barcelona \\ ${ }^{2}$ Universitat de Girona \\ ${ }^{3}$ Centre de Diagnòstic i Atenció Precoz d'Olot \\ ${ }^{4}$ Centre de Salut Mental Infanto-Juvenil de Girona \\ ${ }^{5}$ Centre de Diagnòstic i Atenció Precoç de Sabadell. Consorci Hospitalari Parc Taulí
}

\begin{abstract}
In the last few years, many researchers have studied the presence of common dimensions of temperament in subjects with symptoms of anxiety. The aim of this study is to examine the association between temperamental dimensions (high negative affect and activity level) and anxiety problems in clinical preschool children. A total of 38 children, ages 3 to 6 years, from the Infant and Adolescent Mental Health Center of Girona and the Center of Diagnosis and Early Attention of Sabadell and Olot were evaluated by parents and psychologists. Their parents completed several screening scales and, subsequently, clinical child psychopathology professionals carried out diagnostic interviews with children from the sample who presented signs of anxiety. Findings showed that children with high levels of negative affect and low activity level have pronounced symptoms of anxiety. However, children with anxiety disorders do not present different temperament styles from their peers without these pathologies.

Keywords: temperament, negative affect, activity level, preschool age, anxiety symptoms, anxiety disorders
\end{abstract}

En los últimos años, diversos investigadores han estudiado la presencia de dimensiones temperamentales comunes en sujetos con sintomatología ansiosa. El objetivo del presente estudio es examinar la asociación entre dimensiones temperamentales (afecto negativo y nivel de actividad) y problemas de ansiedad en niños clínicos preescolares. Un total de 38 niños de 3 a 6 años de edad, pertenecientes al Centro de Salud Mental Infanto-Juvenil de Girona y al Centro de Diagnóstico y Atención Precoz de Sabadell y Olot, fueron evaluados por sus padres y por psicólogos. Los padres contestaron a diversas escalas de cribaje y, posteriormente, diversos profesionales en psicopatología clínica infantil realizaron entrevistas diagnósticas a los niños de la muestra que presentaban indicios de ansiedad. Los hallazgos obtenidos muestran que los niños con elevados niveles de afecto negativo y bajos niveles de actividad presentan elevada sintomatología ansiosa. Sin embargo, los niños con trastornos de ansiedad no presentan un estilo temperamental distinto al de los niños sin estas patologías.

Palabras clave: temperamento, afecto negativo, nivel de actividad, edad preescolar, sintomatología ansiosa, trastornos de ansiedad

This article proceeds from the investigation entitled "Early Detection of anxiety disorders in three to twelve-year-old children," financed by the Fondo de Ayudas Sanitarias (FIS 040978). We thank the health personnel from the Centro de Salud Mental InfantoJuvenil of Girona and the Centro de Diagnóstico y Atención Precoz from Sabadell and Olot for their collaboration. We are also grateful to the parents and children who agreed to participate in this research.

Address correspondence concerning this article to: Andrés Laredo García, Departament de Psicologia Clínica i de la Salut, Facultat de Psicologia. Universitat Autònoma de Barcelona, 08193 Bellaterra (Spain). E-mail: andres.laredo@campus.uab.es

Translation: Virginia Navascués Howard 
Knowing which factors are involved in the development and maintenance of anxiety disorders in children would be very useful for their early prevention (Morizot \& Vitaro, 2003). In school-age children and adolescents, between $20 \%$ and $30 \%$ of the infantile clinical population, especially girls, suffer from these pathologies (Anderson, 1994; Costello \& Angold, 1995). However, these disorders can be detected between 4 and 6 years of age (Biederman, Faraone, \& Marrs, 1997). Authors such as Nigg (2006) underscore the presence of certain temperamental dimensions among the risk factors in the development of anxiety problems. From the psychobiological approach of Rothbart and Derryberry (1981), temperament is considered to be a series of individual differences in reactivity (positive and negative) and self-regulation, with a constitutional base but which, over time, receive the influence of inheritance, maturation, and experience. According to Rothbart (1989), the study of temperament, besides the subject's developmental stage, should also analyze the events or stimuli that produce the child's activation and its resulting behavioral reactions. For these authors, reactivity is the series of responses of the emotional, activation, and arousal systems when encountering a certain stimulus, whereas self-regulation comprises the processes that modulate the subject's reactivity (approximation/avoidance, inhibition/attack, attention/inattention, etc.). Consequently, each stimulus is integrated by these two systems. Reactivity-positive (or extroversion) and negative (or negative affect) - and selfregulation are, in turn, made up of more specific temperamental traits, which conform a mechanism of processing and reacting to stimuli that the child implements from birth. According to Rothbart, Ahadi, and Hershey (1994), among the traits that make up temperament are those characterized by negative affect, such as anger/frustration (anger at not getting what one wants), discomfort (feeling uncomfortable when undergoing the sensory characteristics of a stimulus), self-soothing difficulties (having trouble to calm down after feeling upset), and fearfulness (concern or feeling nervous in the presence of certain stimuli or when anticipating pain or discomfort and/or potentially threatening situations).

Although some findings have helped to determine the function of these and other temperamental traits, the area of study that links the preschool child's temperament to subsequent risk of psychopathology is relatively new (Eisenberg, Fabes, \& Guthrie, 2000). The "delay" in this setting may be due to the fact that studies of temperament usually focus on early infancy, whereas investigations in psychopathology basically target school-age children and adolescents (Frick, 2004). For Vasey and Dadds (2001), the low prevalence of anxiety disorders at preschool stages obstructs the study of the relation between temperament and some psychopathological disorders, such as anxiety disorders. However, most of the investigations concentrating on this relation between infantile temperament and anxiety conclude that the temperamental trait of behavioral inhibition correlates the highest with anxiety disorders (Ballespí \& Jané, 2003; Rosenbaum, Biederman, \& Bolsuc-Murphy, 1993; Rosenbaum, Biederman, \& Hirshfeld, 1991; Kagan, Reznick, \& Gibbons, 1989).

However, a growing number of studies show a persistent relation between temperament based on negative affect in early infancy and the emergence of anxiety problems at later ages (Axelson \& Birmaher, 2001; Craske, Poulton, Tsao, \& Plotkin, 2001; Masi et al., 2003; Rapee \& Szollos 2002; Rothbart \& Bates, 1998; Shiner \& Caspi, 2003; Tackett \& Krueger, 2005; Watson, 2005). Negative affect or negative reactivity is the ruling pattern in people with a tendency to feeling "nervous" or terrified in situations where most people act calmly, and these people are susceptible to neurotic problems (Eysenck \& Eysenck, 1985).

Clark, Watson, and Mineka (1994) carried out an exhaustive review of studies that relate personality, temperament, and psychopathology in the adult population. These authors propose a model in which negative affect (which they conceptualize as neuroticism) is considered a general anxiety factor that also involves various internalizing problems. This could explain the comorbidity that is usually observed between anxious and depressive symptomatology. This model has subsequently been considered appropriate to be applied to childhood and adolescent populations, according to the findings of Axelson and Birmaher (2001). Specifically, these researchers observed that the levels of anxiety and depression in school-age children and adolescents correlated highly with a temperament characterized by negative affect. Therefore, some authors, such as Rapee and Szollos (2002), focus their research on the involvement of these more specific traits in the problem of infantile anxiety, as we will describe more extensively below.

Firstly, anger/frustration or temperamental anger is a characteristic trait of children who are easily annoyed when they do not get what they want (Rothbart et al., 1994). In preschool children, a temperament characterized by such anger predicts significant residual variance in internalizing problems (Goldsmith, Aksan, Essex, Smider, \& Mider, 2001). Likewise, Masi et al. (2003) indicate that negative reactivity is more prominent in anxious school-age children and adolescents than in subjects with learning problems or in a communitarian sample (subjects with no detected pathology). Moreover, the parents of children with anxiety disorders also present high levels of anger/frustration, so that this kind of traits seems to "run in families" (Masi et al.).

Likewise, other traits typical of negative affect that are identified by Rothbart et al.'s (1994) psychobiological theory, such as discomfort, difficulty in self-soothing, and fearfulness, have also been linked to anxiety problems, as noted by Rapee and Szollos (2002). According to these authors, the mothers of anxious children state that, all their life, their children have had more difficulties, fears, higher 
levels of discomfort, and poorer levels of self-soothing than children without anxiety symptomatology. With regard to temperamental fearfulness, anxious children seem to present lower thresholds of perception of fear than less anxious children (Muris, Merckelbach, \& Damsma, 2000).

Besides the dimensions of inhibition and negative affect, high level of motor activity in preschool children (especially studied in investigations of problematical temperament) has been related to behavior problems, both internalizing and externalizing (Pettit \& Bates, 1989; Thomas \& Chess, 1977). Likewise, in school-age children and adolescents, a temperament characterized by general high activity, tendency of inhibition and low rhythmicity at meals seems to be a risk factor for the development of anxiety disorders. The presence of restlessness and nervousness in these individuals indicates high general activity (Taboada, Ezpeleta, \& de la Osa, 1998). Other studies report similar tendencies (Maziade, Caperaa, Laplante, Boudreault, \& Thivierge, 1985; Tschann, Kaiser, Chesney, Alkon, \& Boyce, 1996).

The main purpose of this investigation is to study the relation between diverse temperamental dimensions and anxiety problems in a clinical sample of pre-school children (3 to 6 years old). Achievement of this purpose implies attainment of two broad goals. The first is to assess the relation between various temperamental traits (anger/frustration, discomfort, self-soothing, fearfulness, and general activity) and anxiety symptomatology. The second goal is to study the relation between a temperamental pattern characterized by negative affect and motor activity and anxiety disorders.

With regard to these goals, two working hypotheses are proposed. First, we expect to find that, of the total sample, the children who display high levels of traits that are typical of negative affect (anger, discomfort, self-soothing problems, and fear) and high levels of general motor activity will also present high levels of anxiety symptomatology. Second, in contrast to subjects without a diagnosis of anxiety, we expect children with anxiety disorder/s will have a temperamental pattern characterized by high degrees of negative affect and motor activity.
Method

\section{Participants}

Participants in this study were 38 children, ages 3 to 6 years $(M=4.10, S D=0.85)$, who were attended for the first time (new cases) between May and December, 2005, in one of the health centers that collaborated with the study: Infant and Adolescent Mental Health Center of Girona and the Center of Diagnosis and Early Attention of Sabadell and Olot. Children who presented mental retardation or one of the general developmental disorders were excluded from this study.

Geographically, the sample was made up of 17 children from Sabadell, 11 from Olot, and 10 from Girona. Table 1 displays the percentage of participants as a function of gender and age. It can be seen that there were more boys than girls ( $n=29$ and 9, respectively). Of the children, $28.9 \%$ had received psychological help before. Moreover, $55.26 \%$ of the patients admitted having experienced one or several vital stressing events in the last year.

Most of the children came to the center for consultation or psychological assessment, not to receive treatment. Therefore, the parents did not necessarily have to return to the center. Therefore, some of the parents who agreed to participate in the study and who took the scales home with them to complete, did not return them later, with the result that 13 cases were not included in the sample due to lack of data. Therefore, the rate of participation was $74.51 \%$.

\section{Materials}

The Health of the Nation Outcome Scales for Children and Adolescents (HoNOSCA; Gowers et al., 1999) is a rapid clinical screening instrument for the detection of psychopathology in children, which includes 13 broad areas, including clinical anxiety criteria. It should be filled out by a health professional. It has 13 items that rate the intensity of the problem on a 5-point Likert-type scale ranging from

Table 1

Distribution of the Sample as a Function of Gender and Age

\begin{tabular}{cccc}
\hline Age (Years) & Boys & Girls & Total $(\%)$ \\
\hline 3 & 16 & 4 & $20(55.60)$ \\
4 & 10 & 3 & $13(31.58)$ \\
5 & 2 & 1 & $3(7.89)$ \\
6 & 1 & 1 & $2(5.26)$ \\
\hline Total & 29 & 9 & $38(100)$ \\
\hline$\%$ & $76.3 \%$ & $23.7 \%$ & $100 \%$ \\
\hline
\end{tabular}


0 (does not present problem) to 4 (severe or very severe problem). It was developed as a measure of psychopathology to be administered in infantile and adolescent mental health centers, where it has been shown to be reliable and valid (Garralda, Yates, \& Higginson, 2000; Gowers et al.).

The "Escala de sintomatología ansiosa preescolar" (translation: The scale of preschool anxiety symptomatology"; ESAP; Domènech-Llaberia, 1996) was created to screen general anxiety symptomatology in children from 3 to 6 years of age. This dimensional scale has 28 items with three response options (Yes, No, I don't know) that refer to behaviors or situations than can cause fear, avoidance behaviors, complaints, or concern in preschool children. In this study, we used the parents' version, which has good validity indexes and moderate internal consistency $(\alpha=.77)$.

The Early Childhood Inventory-4 (ECI-4; Sprafkin \& Gadow, 1996), parents' version, is a screening instrument for the detection of 13 psychiatric disorders in preschool children (3 to 6 years of age). This inventory is based on the diagnostic criteria of the Diagnostic and Statistical Manual of Mental Disorders (4 ${ }^{\text {th }}$ edition; American Psychological Association, 1994). The scale can be scored in two ways: a 4-point Likert-type scale that measures symptom severity from 0 (not present) to 3 (severe or very severe) or by using cut-off points (based on DSM$I V$ diagnostic criteria), where items are rated either 1 (clinically relevant) or 0 (not clinically relevant). Thus, it can be determined whether the child meets the clinical criteria for psychopathological disorders such as, for example, separation anxiety disorder (Category D), generalized anxiety disorder (Category E), social phobia (Category G), or posttraumatic stress disorder (Category J). The version we used was adapted and validated in the Spanish preschool population by Jané et al. (2006) in a sample of 412 children. It has good construct validity and its internal consistency is generally satisfactory for the parents' and teachers' versions (alpha between .67 and .93), although it is lower for emotional disorders (alpha between .46 and .65).

The Children's Behavior Questionnaire (CBQ; Rothbart et al., 1994) is a parents' report measure made up of 195 items that are rated on a 7-point Likert-type scale, ranging from 1 (totally false) to 7 (totally true). Item content refers to preschool children's temperament based on their behaviors in daily situations in the past six months. Of the 13 temperamental traits assessed by the instrument, we administered the five traits (63 items) that show the highest relation with anxiety symptomatology, according to the bibliographical review carried out: level of motor activity, anger/frustration, discomfort, self-soothing, and fearfulness. In our investigation, we used the version adapted and validated in the Spanish population by Carranza, González, and Hidalgo (2000), which has adequate construct validity and internal consistency indexes (alpha ranging between .67 and .90).
The Interview Guide for Preschool Anxiety Disorders (Jané \& Doménech-Llaberia, 2005) is a series of indications to help the clinical professional carry out an open clinical interview with preschool children, based on the DSM-IV (APA, 1994).

\section{Procedure}

This study is part of a broader research project carried out by the Investigation Unit of Infant and Adolescent Psychopathology. It is a descriptive and cross-sectional investigation. The goal of the first stage is the early detection of anxiety disorders in 3- to 6-year-old children. For this purpose, this research group sought the cooperation of the above-mentioned mental health centers of Sabadell, Olot, and Girona. Subsequently, the supervisors of the research unit and of the mental health centers met to discuss the goals, procedures, and materials to be administered.

The participants were then recruited from the centers. When a child came to the center for the first time, the health supervisors informed the parents about the existence of the study, its goals, and how it would be carried out. If the parents agreed to participate, there were asked to sign their informed consent.

Participants were assessed in two stages. First, we wished to identify the children who were at risk for anxiety problems. For this purpose, the clinical psychologists who attended the participants completed the HoNOSCA (Gowers et al., 1999) while the parents filled in the ECI-4 (Sprafkin \& Gadow, 1996). Thus, the HoNOSCA and the ECI- 4 were used to determine which children had sufficient symptomatology to meet the criteria for anxiety disorders (and were therefore referred to the second phase of the study). The decision criterion to interview the child was scoring 2 or more points in Item 9 of the HoNOSCA and/or meeting the ECI-4 criteria for one of the anxiety disorders. These steps were established by the authors of the psychopathological screening instruments. The ESAP (Doménech-Llaberia, 1996) and the CBQ (Rothbart et al., 1994) were also administered to the parents. Most of the questionnaires were completed in the presence of a psychologist in the center offices. However, some parents did not wish to fill in the questionnaires at the center, so they were requested to do so at home. It was agreed that they would clear up any doubts when returning the questionnaires.

In the second stage, the children who had sufficient symptomatology to meet anxiety disorder criteria were scheduled for the diagnostic interview. This interview was carried out with the double-blind procedure. The children who really had anxiety disorders were thus identified and this group's scores were compared with those of the rest of the sample (children without such disorders). 


\section{Statistical Analyses}

The data were analyzed with the SPSS version 13.0 statistical package. In all the statistical tests applied, the significance level was $p<.05$.

First, the relation between the temperamental traits and anxiety symptomatology was analyzed in the entire sample ( $N=38$, normally distributed, according to the KolmogorovSmirnov test). Pearson's correlations were calculated between the CBQ scores and the anxiety category scores of the ECI4 (separately and conjointly) and Item 9 of the HoNOSCA. In the case of the ESAP, as it is an ordinal scale (Yes, No, I don't know), Spearman's correlation were calculated between its scores and the CBQ scores. The CBQ scores represent the means of all the items of each subscale administered to the children, as mentioned by the authors (Rothbart et al., 1994).

Subsequently, the children were classified as a function of the presence/absence of a diagnostic approximation of anxiety disorders, obtained through the clinical interview. The statistical tests indicate that some group distributions are not normal and the homogeneity of variances is not assumed. Therefore, in order to compare the temperamental traits between the groups of children with and without anxiety disorders, the data were analyzed by means of nonparametric tests.

\section{Results}

\section{Description of the Clinical Sample}

Of the 38 participants that comprise the sample, 16 present signs of clinical anxiety based on the screening instruments used as anxiety criterion (HoNOSCA and ECI4). Of them, 9 children were diagnosed as having anxiety disorders in the second phase of the study, which indicates a prevalence of $23.68 \%$ in the clinical sample. Hence, 76.32 $\%$ of the participants did not meet the criteria for these pathologies. The distribution of the anxiety disorders was as follows: separation anxiety disorder (33.33\%), generalized anxiety disorder $(22.22 \%)$, comorbidity of both disorders (22.22\%), simple phobia (7.14\%), and social phobia (7.14\%).

Table 2 displays the scores in the screening instruments obtained by the groups of children with and without anxiety disorders, and the between-group means comparison performed with Mann-Whitney's $U$ test. In this table, it can be seen that the group of children with anxiety disorders clearly obtained higher scores in most of the scales than the children without this diagnosis.

\section{Relation between Temperamental Traits and Anxious Symptomatology in the Total Sample}

Bivariate correlations were calculated to appraise the relation among the temperamental traits and anxiety symptomatology. In Table 3 is displayed the correlations matrix of the variables of this study. It can be seen that the set of temperamental traits that conform negative affect showed a significant relation, of moderate intensity, with anxiety symptomatology.

More specifically, anger/frustration had positive correlations with generalized anxiety symptomatology $(r=$ $.327, p<.01)$ and with social phobia $(\mathrm{r}=.336, p<.05)$. Likewise, the data showed that discomfort had the largest number of significant positive correlations with the anxiety scales employed. More concretely, discomfort was moderately related to separation anxiety disorder $(r=.362$, $p<.05)$, generalized anxiety disorder $(r=.559, p<.05)$, posttraumatic stress disorder $(r=.399, p<.01)$, the set of total anxiety categories of the ECI-4 $(r=.508, p<.01)$, and to the total ESAP score $(r=.600, p<.01)$. Moreover,

Table 2

Comparison of Anxiety Scores of Children with and without Anxiety Disorders

\begin{tabular}{|c|c|c|c|c|}
\hline Instrument & $\begin{array}{l}\text { Children with } \\
\text { anxiety disorders } \\
(n=9) \\
M\end{array}$ & $\begin{array}{l}\text { Children without } \\
\text { anxiety disorders } \\
\left(\begin{array}{c}n=29) \\
M\end{array}\right.\end{array}$ & Mann-Whitney $U$ & $p$ (bilateral) \\
\hline ECI-4 - Category D (separation anxiety) & 6.77 & 5.07 & 105.00 & .379 \\
\hline ECI-4 - Category E (generalized anxiety disorder) & 6.33 & 3.83 & 506.50 & .041 \\
\hline ECI-4 - Category G (social phobia) & 2.78 & 1.31 & 57.00 & .010 \\
\hline ECI-4 - Category J (posstraumatic stress disorder) & 0.67 & 0.66 & 117.00 & .534 \\
\hline ECI-4 - Total Anxiety Categories & 16.56 & 10.86 & 505.50 & .039 \\
\hline HoNOSCA - Emotional Symptoms & 2.33 & 1.14 & 487.00 & .005 \\
\hline ESAP Total Score & 10.78 & 8.79 & 530.50 & .228 \\
\hline
\end{tabular}

Note. ECI-4 = Early Childhood Inventory-4; HoNOSCA = Health of the Nation Outcome Scales for Children and Adolescents; ESAP = "Escala de sintomatología ansiosa preescolar" (Scale of preschool anxiety symptomatology). 
Table 3

Correlations between Temperamental Traits as Measured by the CBQ and Anxiety Symptomatology as Measured by the ECI-4, the HoNOSCA, and the ESAP in the Entire Sample

\begin{tabular}{lccccc}
\hline & \multicolumn{4}{c}{ CBQ Temperamental Traits } \\
\cline { 2 - 6 } Anxiety Symptomatology & Anger/frustration & Discomfort & Self-soothing & Fearfulness & Motor activity \\
\hline ECI-4 - Category D (Separation anxiety) & .174 & $.362 *$ & -.110 & .260 & -.027 \\
ECI-4 - Category E (Generalized anxiety disorder) & $.327 * *$ & $.559 *$ & -.262 & .264 & -.115 \\
ECI-4 - Category G (Social phobia) & $.336 *$ & .089 & -.184 & .040 & $-.450 * *$ \\
ECI-4 - Category J (Posttraumatic stress disorder) & .014 & $.399 * *$ & -.268 & -.045 & -.047 \\
ECI-4 - Total Anxiety Categories & .166 & $.508 * *$ & -.248 & .242 & -.152 \\
HoNOSCA - Emotional and related symptoms & -.108 & .256 & -.285 & .035 & -.258 \\
ESAP & -.015 & $.600 * *$ & $-.322^{*}$ & $.477 *$ & -.027 \\
\hline
\end{tabular}

Note. $\mathrm{CBQ}=$ Children's Behavior Questionnaire; ECI-4 = Early Childhood Inventory-4; HoNOSCA = Health of the Nation Outcome Scales for Children and Adolescents; ESAP = "Escala de sintomatología ansiosa preescolar" (Scale of preschool anxiety symptomatology). All the correlations are Pearson's correlations, except for the ESAP, where they are Spearman's correlations, as responses in this scale are ordinal. $N=38$.

$* p<.05$ (bilateral). $* * p<.01$ (bilateral).

Table 4

Comparison of Mean Temperamental Traits as a Function of the Presence or Absence of a Diagnosis of Anxiety Disorder

\begin{tabular}{|c|c|c|c|c|c|}
\hline \multirow[b]{2}{*}{ Diagnosis of Anxiety Disorder } & \multicolumn{5}{|c|}{ Temperamental Traits (CBQ) } \\
\hline & $\begin{array}{l}\text { Anger/frustration } \\
\qquad M(S D)\end{array}$ & $\begin{array}{l}\text { Discomfort } \\
M(S D)\end{array}$ & $\begin{array}{l}\text { Self-soothing } \\
\qquad M(S D)\end{array}$ & $\begin{array}{l}\text { Fearfulness } \\
\qquad M(S D)\end{array}$ & $\begin{array}{l}\text { General motor activity } \\
\qquad M(S D)\end{array}$ \\
\hline Children without Anxiety Disorder $(n=29)$ & $4.44(0.85)$ & $4.18(0.91)$ & $4.49(0.82)$ & $3.87(0.86)$ & $4.59(0.91)$ \\
\hline Children with Anxiety Disorder $(n=9)$ & $4.18(0.90)$ & $4.22(0.38)$ & $4.39(0.56)$ & $4.22(1.07)$ & $4.10(0.88)$ \\
\hline Total $(N=38)$ & $4.38(0.86)$ & $4.19(0.81)$ & $4.46(0.76)$ & $3.96(0.91)$ & $4.47(0.91)$ \\
\hline Mann-Whitney $U$ & 112.00 & 119.50 & 119.50 & 102.50 & 88.00 \\
\hline
\end{tabular}

Note. $\mathrm{CBQ}=$ Children's Behavior Questionnaire.

None of the mean differences were statistically significant at $p<.05$.

general anxiety symptomatology (as assessed by the ESAP) presented significant negative correlations with the level of self-soothing $(r=-.322, p<.05)$ and positive correlations with fearfulness $(r=.477, p<.01)$. Consequently, the more fearful children or those who presented more self-soothing difficulties obtained higher indexes of preschool anxiety in comparison to children without these traits.

With regard to the level of motor activity, there was a negative relation between this temperamental dimension and social phobia $(r=-.450, p<.01)$. That is, the higher the children's levels of motor activity, the lower their scores in social anxiety symptomatology.

\section{Comparison of Temperament Patterns in the Anxious and Non-Anxious Groups of Children}

In order to study the possible divergences between the temperamental patterns of children with and without anxiety disorders, the temperamental trait means of both groups were compared, as displayed in Table 4. Using the nonparametric
Mann-Whitney U test, no statistically significant group differences were obtained in the temperamental traits. In other words, the temperamental patterns of anxious and nonanxious children are not different.

\section{Discussion}

As mentioned above, the first goal of the study was to determine the possible relation between temperamental traits and anxiety symptomatology in a clinical sample. On the one hand, the results of this investigation indicate that, as expected, children with high negative affect suffer high levels of anxious symptomatology. However, in contrast to our hypothesis, there was an inverse relation between the level of motor activity and anxiety: the less active children had higher levels of anxiety.

There are several explanations that may justify these results, both for the positive and for the negative data. On the one hand, our findings are in accordance with those 
obtained in previous investigations of children, which sustain that this kind of symptomatology is observed more in individuals who, temperamentally, present higher levels of anger/frustration (Goldsmith et al., 2001), discomfort, selfsoothing difficulty (Rapee \& Szollos, 2002; Teerikangas, Aronen, Martin, \& Huttunen, 1998), and fearfulness (Goldsmith \& Lemery, 2000; Muris et al., 2000). According to Nelson, Martin, Hodge, Havill, and Kamphaus (1999), and subsequently underscored by Rapee and Szollos (2002), anxiety symptomatology emerges from a temperamental trajectory whose essential characteristic is negative affect. For these authors, children at risk for anxiety disorders are those who, from early infancy, show high levels of anger and discomfort. According to Rothbart (1989), these children are characterized by a special sensitivity to negative stimuli, to which they react with anger, discomfort, or fear. These are children with self-regulatory difficulties, who are incapable of controlling their reactions and self-soothing when faced with certain negative stimuli. Over time, this temperament causes these individuals to generalize their discomfort to many other situations, and to tend towards anxiety symptomatology. Following the proposals of Nelson et al. and Rapee and Szollos it is not surprising that, in this study, the level of discomfort had the highest correlations with preschool anxiety symptomatology in the total sample. Unfortunately, the design of this study does not allow us to infer causality and, therefore, to provide data about the existence of a temperamental trajectory that leads to anxiety problems.

With regard to the relation between motor activity and anxiety, in contrast to various authors (Pettit \& Bates, 1989; Taboada et al., 1998; Thomas \& Chess, 1977), in this study, we found that low motor activity was related to high levels of anxiety, more precisely, symptomatology of social phobia. A possible explanation for these data is that some items of the motor activity dimension of the CBQ may include behaviors of implicit social interaction (i.e., "When he is outside, he/she plays actively with other children"). Therefore, there may be a component of behavioral inhibition mediating the relation between activity level and social anxiety because, as noted by Ballespí and Jané (2003), inhibited children reduce their motor activity in social contexts.

With reference to the second goal of this investigation, we wished to study the relation between a specific temperamental pattern (characterized by negative affect and motor activity) and anxiety disorders. In contrast to our expectations, our findings do not confirm that children with anxiety disorders have a different temperamental pattern from children without such a diagnosis. Surprisingly, the data revealed no statistically significant differences in the levels of motor activity or negative affect of the groups of clinical children. These results are not in accordance with those of the studies reviewed (Anthony, Lonigan, Hooe, \& Phillips, 2002; Axelson \& Birmaher, 2001; Taboada et al.,
1998; Masi et al., 2003, Maziade et al., 1985). In all these investigations, pronounced negative affect or high motor level was related to anxious pathologies. However, their results proceed from samples of school-age children and adolescents, whereas, in our study, $87.2 \%$ of the participants were children of 3 and 4 years of age. Therefore, the investigations are not very comparable.

One could be critical of the data obtained which indicate the unspecificity of the temperamental patterns in children with and without anxiety disorders and one could query about the cause of this. Given its biological and innate nature, temperament is more visible in younger subjects. In most of the studies, including this one, children are assessed in early infancy by means of information provided by their parents, who are not the best source to assess children's behavior. As noted by Gándara (2005), the best source is the children themselves, but children have no self-assessment capacity before the age of 7 , at which time temperament is very much influenced by environmental aspects. In studies with school children and adolescents, this problem does not exist because both the measures of risk factors and psychopathology are completed by the youths themselves. In our study, this was not possible and we had to use the information provided by several sources and different methods: the parents assessed their children's temperamental characteristics by means of questionnaires, whereas the clinical psychologists analyzed the psychopathological variables by means of interviews of the children (in the presence of their parents to clarify any doubts). Consequently, the absence of a relation between temperament and anxiety disorders may be due to two main factors: First, a large part of the information of the study was provided by the parents and, according to Olson, Bates, and Bayles (1986), there is some general weakness in data obtained from adults. Moreover, using different information sources may cause problems because of low between-subject consistency, as noted by Goldsmith et al. (2001). In their investigation, they reported that the between-subject consistency of the predictors of internalizing tendencies is usually very modest. Therefore, these authors recommend that, when feasible, the measures to be analyzed should come from a single informer, thus facilitating the obtainment of more powerful and numerous relations. In short, the fact that we used information provided by different sources and not directly from the analyzed subject (that is, the child) can explain why no temperamental differences were found between children with and without anxious pathology.

In addition to the above, in this study other limitations should be taken into account for future investigations. This investigation is a pioneer in the study of the relation between temperament, especially characterized by negative affect, and anxious problems in clinical children of very early ages (3-4 years). As indicated by Frick (2004), this is an area of study yet to be explored. Therefore, this study is an attempt to become a starting point from which to 
develop new investigations that reduce the limitations encountered herein. The importance of this type of investigations is that, on the one hand, they allow us to gain more in-depth knowledge of infantile psychopathology, and, more specifically, of the link between temperamental factors and psychological alterations at early ages. On the other hand, early identification of the temperamental traits, such as high negative affect, that are linked to pathological symptomatology may help to create an early intervention program for children's temperamental difficulties, such as the one proposed by Rapee and Jacobs (2002), thus avoiding the development of future problems.

To sum up, the present investigation presents some signs that various temperamental dimensions, such as high negative affect or low motor activity, are related to high anxiety symptomatology. However, it was not confirmed that children with anxiety disorders have a different temperamental pattern from that of children without such pathologies. As this is a pioneer study in a novel setting, there are various limitations (low between-subject consistency, informers other than the patients, scarcity of validated instruments in Spain to assess preschool children, etc.) that recommend viewing these data with caution. These limitations should be a particular reference for future investigators who are concerned with the prevention of problems in preschool children. Thus, large samples should be used, both clinical and communitarian (children with no diagnosed clinical pathology), instruments should be validated that allow us to better comprehend the preschool child, and complementary techniques should be used to obtain direct information from the patient, without intermediaries (e.g., direct observation of the child).

\section{References}

American Psychological Association. (1994). Diagnostic and statistical manual of mental disorders $\left(4^{a}\right.$ ed.) (DSM-IV). Washington, DC: Author.

Anderson, J.C. (1994). Epidemiological issues. In T.H. Ollendick, N.J. Kingy, \& W. Yule (Eds.), International handbook of phobic and anxiety disorders in children and adolescents (pp. 43-66). New York: Plenium Press.

Anthony, J.L., Lonigan, C.J., Hooe, E.S., \& Phillips, B.M. (2002). An affect-based, hierarchical model of temperament and its relations with internalizing symptomatology. Journal of Clinical Child and Adolescent Psychology, 31, 480-490.

Axelson, D., \& Birmaher, B. (2001). Relation between anxiety and depressive disorders in childhood and adolescence. Depression and Anxiety, 14, 67-78.

Ballespí, S., \& Jané, M.C. (2003). Inhibició, psicopatologia i alteracions del llenguatge. In E. Domènech-Llaberia, J.E.Obiols, M.C. Jané \& S. Subirà, Actualizacions en Psicopatologia Clínica (pp. 41-78). Barcelona: Universidad Autónoma de Barcelona.
Biederman, J., Faraone, S.N., \& Marrs, A. (1997). Panic disorder and agoraphobia in consecutively referred children and adolescents. Journal of the American Academy of Child and Adolescent Psychiatry, 36, 214-223.

Biederman, J., Rosenbaum, J.F., \& Bolsuc-Murphy, E.A. (1993). A 3-year follow-up of children with and without behavioral inhibition. Journal of the American Academy of Child and Adolescent Psychiatry, 32, 814- 821.

Carranza, J.A., González, C., \& Hidalgo, M.D. (2000, July). Spanish adaptation of the Children Behavior Assessment Questionnaire. Poster presented at the XII Conference of Infantile Psychiatry and Psychology. Stockholm, Sweden.

Clark L.A., Watson, D., \& Mineka, S. (1994). Temperament, personality, and the mood and anxiety disorders. Journal of Abnormal Psychology, 103,103-115.

Costello, E.J., \& Angold, A. (1995). Epidemiology. In J.S. March (Ed.), Anxiety disorders in children and adolescents (pp. 109124). New York: Guilford Press.

Craske, M.G., Poulton, R., Tsao, J.C.I., \& Plotkin, D. (2001) Paths to panic-agoraphobia: An exploratory analysis from age 3 to 21 in an unselected birth cohort. American Journal of Child and Adolescent Psychiatry, 40, 556-563.

Domènech-Llaberia, E. (1996). Escala de Sintomatología Ansiosa Preescolar (ESAP). Unpublished manuscript.

Eisenberg, N., Fabes, R.A., \& Guthrie, I.K. (2000). Dispositional emotionality and regulation: Their role in predicting quality of social functioning. Journal of Personality and Social Psychology, 78, 136-57.

Eysenck, H., \& Eysenck, S. (1985). Personality and individual differences. New York: Plenum. (Spanish translation: Personalidad y diferencias individuales. Madrid: Pirámide, 1987).

Frick, P.J. (2004). Integrating research on temperament and childhood psychopathology: Its pitfalls and promise. Journal of Clinical Child and Adolescent Psychology, 33, 2-7.

Gándara, V.B. (2005). Temperamento. In L. Ezpeleta (Ed.), Factores de riesgo en psicopatología del desarrollo (pp. 113-145). Barcelona: Masson.

Garralda, M.E., Yates, P., \& Higginson, I. (2000), Child and adolescent mental health service use. HoNOSCA as an outcome measure. Britain Journal of Psychiatry, 177, 52-58.

Goldsmith, H.H., Aksan, L., Essex, M., Smider, N., \& Mider N.A. (2001). Temperament and socio-emotional adjustment to kindergarten: A multi-informant perspective. In T.D. Wachs \& G.A. Kohnstamm (Eds.), Temperament in context (pp. 103138). Mahwah, NJ: Erlbaum

Goldsmith, H.H., \& Lemery, K.S. (2000). Linking temperamental fearfulness and anxiety symptoms: A behavior-genetic perspective. Biological Psychiatry, 48, 1190-1209.

Gowers, S.G., Harrington, R.C., Whitton, A., Lelliott, P., Beevor, A., Wing, J., \& Jezzard, R. (1999). Brief scale for measuring the outcomes of emotional and behavioural disorders in children. Health of the Nation Outcome Scales for Children and Adolescents (HoNOSCA). The British Journal of Psychiatry, 174, 413-416. 
Jané, M.C., Canals, J., Ballespí, S., Viñas, F., Esparó, G., \& Domènech-Llaberia, E. (2006). Parents' and teachers' reports of DSM-IV psychopathological symptoms in preschool children. Social Psychiatry and Psychiatric Epidemiology, 41, 386-393.

Jané, M.C., \& Domènech-Llaberia, E. (2005). Entrevista de trastornos de ansiedad preescolar en base a criterios diagnòsticos del DSM-IV. Unpublished manuscript.

Kagan, J., Reznick, J.S., \& Gibbons, A. (1989). Inhibited and uninhibited types of children. Child Development, 60, 838-845.

Masi, G., Mucci, L., Favilla, L., Brovedani, P., Millepiedi, S., \& Perugi, G. (2003). Temperament in adolescents with anxiety and depressive disorders and in their families. Child Psychiatry and Human Development, 33, 245-251.

Maziade, M., Caperaa, P., Laplante, B., Boudreault M., \& Thivierge, J. (1985). Value of difficult temperament among 7-years-olds in the general population for predicting psychiatric diagnosis at age 12. American Journal of psychiatry, 142, 943-946.

Morizot, J., \& Vitaro, F. (2003). Temperament et components perturbateurs chez l'enfant: une reuve critique des études longitudinales. Bulletin de Psychiatry, 56, 69-78.

Muris, P., Merckelbach, H., \& Damsma, E. (2000). Threat perception bias in nonreferred socially anxious children. Journal of Clinical Child Psychology, 29, 348-359.

Nelson, B., Martin, R.P., Hodge, S., Havill, V., \& Kamphaus, R. (1999). Modeling the prediction of elementary school adjustment from preschool temperament. Personality and individual differences, 26, 687-700.

Nigg, J.T. (2006). Temperament and developmental psychopathology. Journal of Child Psychology and Psychiatry, 47, 395-422.

Olson, S.L., Bates, J.E., \& Bayles, K. (1986, April). Prediction of social and cognitive competence at age 6 from early motherchild interaction. Presented at The Fifth Biennial International Conference on Infant Studies, Los Angeles.

Pettit, G.S., \& Bates, J.E. (1989). Family interaction patterns and children's behavior problems from infancy to 4 years. Development and psychopathology, 25, 413-420.

Rapee, R.M. (2002). The development and modification of temperamental risk for anxiety disorders: Prevention of a lifetime of anxiety? Biological Psychiatry, 52, 947-957.

Rapee R.M., \& Szollos A.A. (2002). Developmental antecedents of anxiety in childhood. Behaviour Change, 19, 146-157.

Rosenbaum, J.F., Biederman, J., \& Bolduc-Murphy, B.A., (1993): Behavioral inhibition in childhood: A risk factor for anxiety disorders. Harvard Review of Psychiatry, 1, 2-16.

Rosenbaum J.F., Biederman J., \& Hirshfeld, D.R. (1991). Further evidence of an association between behavioral inhibition and anxiety disorders: Results from a family study of children from a non-clinical sample. Journal of Psychiatric Research, $23,49-65$.
Rothbart, M.K. (1989). Temperament in childhood: A framework. In G. Kohnstamm, J. Bates, \& M.K. Rothbart (Eds.), Temperament in childhood (pp. 59-73). Chichester, UK: Wiley.

Rothbart, M.K., Ahadi, S.A., \& Hershey, K.L. (1994). Temperament and social behavior in childhood. Merrill-Palmer Quarterly, 40, 21-39.

Rothbart, M.K., \& Bates, J.E. (1998). Temperament. In N. Eisenberg (Ed.), Handbook of child psychology: Vol. 3. Social, emotional, and personality development ( $5^{\text {th }}$ ed., pp. 105-176). New York: Wiley.

Rothbart, M.K., \& Derryberry, D. (1981). Development of individual differences in temperament. In M.E. Lamb \& A.L. Brown (Eds.), Advances in developmental psychology (Vol. 1., pp. 37-86). Hillsdale, NJ: Erlbaum.

Shiner, R., \& Caspi, A. (2003). Personality differences in childhood and adolescence: Measurement, development, and consequences. Journal of Child Psychology and Psychiatry, 44, 2-32.

Sprafkin, J., \& Gadow, K.D. (1996). Early Childhood Symptom Inventories manual. Stony Brook, New York: Checkmate Plus.

Taboada, A.M., Ezpeleta, L., \& de la Osa, N. (1998). Trastornos por ansiedad en la infancia y adolescencia: factores de riesgo. Ansiedad y estrés, 4, 1-16.

Teerikangas, O.M., Aronen, E.T., Martin, R.P., \& Huttunen, M.O. (1998). Effects of infant temperament and early intervention on the psychiatric symptoms of adolescents. Journal American Academy of Child and Adolescent Psychiatry, 37, 1070-1076.

Tackett, J.L., \& Krueger, R.F. (2005). Interpreting personality as a vulnerability for psychopathology: A developmental approach to the personality-psychopathology relationship. In B.L. Hankin \& J.R.Z Abela (Eds.), Development of psychopathology: A vulnerability-stress perspective (pp. 199-214). Thousand Oaks, CA: Sage.

Thomas, A., \& Chess, S. (1977). Temperament and development. New York: Brunner/Mazel.

Tschann, J.M., Kaiser, P., Chesney, M.A., Alkon, A., \& Boyce, T. (1996). Resilience and vulnerability among preschool children: Family functioning, temperament, and behavioral problems. Journal American Academy of Child and Adolescent Psychiatry, 35, 184-192.

Vasey, M.W., \& Dadds, M.R. (2001). The developmental psychopathology of anxiety. New York: Oxford University Press.

Watson, D. (2005). Rethinking the mood and anxiety disorders: A quantitative hierarchical model for DSM-V. Journal of Abnormal Psychology, 114, 522-536.

Received November, 15, 2006 Revision received February, 12, 2007 Accepted March, 26, 2007 